\title{
A semantic solution to the problem with aesthetic testimony
}

Article

Accepted Version

Andow, J. (2015) A semantic solution to the problem with aesthetic testimony. Acta Analytica, 30 (2). pp. 211-218. ISSN 0353-5150 doi: https://doi.org/10.1007/s12136-014-0238-4 Available at https://centaur.reading.ac.uk/42078/

It is advisable to refer to the publisher's version if you intend to cite from the work. See Guidance on citing.

Published version at: http://dx.doi.org/10.1007/s12136-014-0238-4

To link to this article DOI: http://dx.doi.org/10.1007/s12136-014-0238-4

Publisher: Springerlink

All outputs in CentAUR are protected by Intellectual Property Rights law, including copyright law. Copyright and IPR is retained by the creators or other copyright holders. Terms and conditions for use of this material are defined in the End User Agreement.

\section{www.reading.ac.uk/centaur}

\section{CentAUR}

Central Archive at the University of Reading

Reading's research outputs online 


\title{
A Semantic Solution to the Problem with Aesthetic Testimony
}

\author{
James Andow
}

May 25, 2015

\begin{abstract}
There is something peculiar about aesthetic testimony. It seems more difficult to gain knowledge of aesthetic properties based solely upon aesthetic testimony than it is in the case of other types of property. In this paper, I argue that we can provide an adequate explanation at the level of the semantics of aesthetic language without defending any substantive thesis in epistemology or about aesthetic value/judgement. If aesthetic predicates are given a non-invariantist semantics, we can explain the supposed peculiar difficulty with aesthetic testimony.
\end{abstract}

\section{Intro}

Here's paradigmatic case of attaining knowledge via testimony. A has a belief with the content p. A knows that p. A tells B, 'p', expressing that belief. B comes to know that $\mathrm{p}$ (on the basis of the content of A's assertion). Relying on the testimony of people who know will typically, barring doxastic irresponsibility, give you knowledge yourself-at least about mundane matters. ${ }^{1}$ However, intuitively, it is rather more difficult to attain knowledge about aesthetic properties based solely upon testimony. Relatedly, assertions such as, 'the film is absolutely superb, although I have never seen it,' are intuitively unacceptable. ${ }^{2}$

It seems that any successful account of aesthetic testimony will have something to say about these intuitions. In the currently raging debates on aesthetic testimony these intuitions tend to be treated, if not as data, at least as something to be explained-perhaps explained away (see the review article, Robson, 2012). Various types of explanation are available. Some draw on the idea that some sort of acquaintance is necessary for proper aesthetic judgement. I can't form a belief whether a painting is incredibly beautiful, so goes the thought, unless

\footnotetext{
${ }^{1}$ 'Doxastic responsibility' is borrowed from MacFarlane (2005) who in turn borrowed it from MacDowell (1998). The purpose is to exclude cases in which B blindly accepts that $\mathrm{p}$, ignoring evidence she has that A speaks falsely, for example.

${ }^{2}$ Interestingly, assertions about the past seem to be exceptional here, e.g., 'Helen of Troy was exceptionally beautiful, although I don't know what she looked like'. Thanks to Jon Robson for pointing this out.
} 
I have seen it. ${ }^{3}$ Others argue that testimonial aesthetic knowledge is available, but unusable (Hopkins, 2006, 2011). ${ }^{4}$ Others argue that knowledge is perfectly attainable, but that reliable testimony is rare as few have sufficient expertise (Meskin, 2004).

In this paper, I present a novel way to account for these intuitions. I show that a relativist account of the semantics of aesthetic predicates can explain the intuitive appeal of two positions: (i) that taking testimony on aesthetic matters is more problematic than taking testimony on many other kinds of issue, and (ii) that there is something infelicitous about assertions such as 'the film is absolutely superb, although I have never seen it'. I distinguish between various forms of relativism about the truth of sentences containing aesthetic predicates such as 'is absolutely lovely' which say that the truth of such sentences is relative to either context of use or context of assessment. ${ }^{5}$ I explain how each of them can account for the intuitiveness of (i) and (ii). I do not provide independent motivation for a relativist treatment of such predicates, although the fact they can explain the intuitiveness of (i) and (ii) should be seen as positive features of the view. ${ }^{6}$

The idea that relativism of some form or other will be able to provide an easy solution to the problem of aesthetic testimony might seem obvious, and relativist options have been considered elsewhere before (see, e.g., Meskin, 2004). However, it is important to recognise that the type of solution considered here does not involve an appeal to aesthetic relativism, i.e., relativism about aesthetic value. ${ }^{7}$ This paper argues that relativism can solve the problem, without getting into the nature of aesthetic belief/judgement, delving deeply into the epistemology of testimony, or going straight for a relativism about aesthetic value (contrast with Hopkins, 2001; McGonigal, 2006; Meskin, 2004).

\section{Semantics}

An invariantist semantics for aesthetic predicates says that neither the content expressed by the sentences in which they appear, nor the truth of that content, vary with either the context of use or with context of assessment (absent any other context sensitive terms). Such an account says that 'the tarantella is a lovely dance' expresses the same proposition regardless of who utters it or who assess it for truth. It also says that that proposition has an invariant truth value-it is either true or false.

\footnotetext{
${ }^{3}$ Wollheim's original statement of the acquaintance principle admits exceptions to the rule that judgements of aesthetic value are not transmissible from one person to another 'within very narrow limits' (Wollheim, 1980). However, it is not clear what these limits are and the exceptionless version suffices for my purposes.

${ }^{4}$ For an objection to this view, see Robson (2013a).

${ }^{5}$ I should note I don't presume against the optimist-she who thinks that attaining knowledge of aesthetic properties based solely upon aesthetic testimony is relatively easy-as even they tend to think that testimony about matters aesthetic is more problematic than testimony in general (e.g., Laetz, 2008; Meskin, 2004; Robson, 2013a,b).

${ }^{6}$ In the following, I present four types of view. I don't aim to decide which is the best vis-à-vis being able to provide a descriptively adequate semantic account of aesthetic predicates here. However, I suspect that a non-indexical assessor relativism is the most promising.

${ }^{7}$ See MacFarlane (2014, pp.147-8) for a related discussion.
} 
I propose treating the truth of sentences containing aesthetic predicates to be non-invariant. ${ }^{8}$ I shall consider both speaker and assessor relativism. ${ }^{9}$ I'll argue that this treatment promises to explain (i) why it is intuitive that there is some barrier to gaining aesthetic knowledge via aesthetic testimony, and (ii) the infelicity of certain assertions (such as above).

There are two ways to make the truth of a sentence contextually variant. One way is to suggest that such sentences contain an indexical expression which modifies the content relative to some feature of either the context of use or context of assessment. We shall call this type of view 'indexicalist'. ${ }^{10}$ Another way to do this is to say that, unbeknownst to us, the truth of propositions expressed by sentences containing such predicates is relative to either the context of use or context of assessment. We shall call this type of view 'non-indexicalist'. ${ }^{11}$

A fully developed view which posits contextual variance in sentence truth should say something about which features of a context might be doing the work. I don't think it matters which I choose for the sake of this paper. Just so that I have an example to work with, I'll say that what is doing the work is the standard of taste of the agent of the context. ${ }^{12} \mathrm{We}$ may say, 'The tarantella is a lovely dance,' is true relative to my standard of taste, and false relative to my daughter's. ${ }^{13}$

The distinction between speaker and assessor relativism concerns whose contexts are relevant to sentence truth. Speaker relativism is the most familiar view (it is often known as contextualism). This says that the truth of a sentence as used at a context is fixed by that context of use, by the speaker's context, and that the context of assessment is irrelevant to sentence truth. 'The tarantella is a lovely dance,' is true relative to my standard of taste, and false relative to my daughter's. The sentence says something true when I say it, and false when my daughter says it. Assessor relativism, on the other hand, says that the truth of a sentence is fixed only relative to a context of assessment (in addition to the speaker's context). When I say, 'The tarantella is a lovely dance,' the sentence is true as assessed by me, and false as assessed by my daughter.

So there are four views on the table. The truth of sentences containing aesthetic predicates is relative to the context of (i) the speaker (indexically), (ii) the speaker (non-indexically), (iii) an assessor (indexically), and (iv) an assessor (non-indexically). I argue that each can account for both sets of intuitions.

First, consider the first set of intuitions. I'll consider what each form of truth relativism

\footnotetext{
${ }^{8}$ I am hardly the first. See, e.g., Lasersohn (2005); MacFarlane (2014); Smith (2010, 2012).

${ }^{9}$ See MacFarlane (2014) for a developed exposition of these types of semantics.

${ }^{10} \mathrm{~A}$ relativism of this broad type is considered by Matravers (2010).

${ }^{11}$ I taxonomise these 'relativist' views in broadly the same way as MacFarlane (2014). I am simplifying somewhat for sake of clarity. In MacFarlane's discussion of nonindexicalism a proposition can be said to be true only relative to a context. It is then the accuracy of utterances which is said to be relative to the context of assessment (by the relativist) or the context of use (by the contextualist).

${ }^{12}$ Obviously, this is a simplification. An agent may choose to defer to the tastes of others. The relevant standard of taste may be the taste of some contextually salient appreciator or set of appreciators. Nonetheless, it is still either the context of assessment or the context of use which determines whose tastes are relevant, even if it is not the tastes of the agent of the context.

${ }^{13}$ I should note, for my wife's sake, that I have no daughter (at the time of writing). I simply liked the idea of telling flagrant falsehoods in a paper on testimony.
} 
says in turn. I'll use a paradigmatic case of testimony. I believe the tarantella is lovely. I tell my daughter 'the tarantella is a lovely dance'. She then forms a belief with the same content as my belief on the basis of my asserting that content.

Indexical speaker relativism: This view supposes that 'is a lovely dance' contains a hidden indexical. It modifies the content such that the content I express is something like /the tarantella is a lovely dance for James Andow). My daughter forms a belief with the same content.

First thing to note: this is a really implausible story. This sort of view will have to hold that the context sensitivity is not completely transparent to us-to posit a degree of semantic blindness. ${ }^{14}$ If aesthetic predicates are indexicals, then they are not like 'my mother'. ${ }^{15}$ Yet, somehow, my daughter has formed a belief with the same content I asserted, despite having no obvious means of accessing the exact asserted content. More importantly, however, this just doesn't seem like a good case of aesthetic testimony. My daughter hasn't formed a belief concerning her tastes at all-it is akin only to believing that I like the dance.

Second, if, in a more plausible version of the story, my daughter instead forms a belief with the content expressed when she utters the same sentence I uttered, 'The tarantella is a lovely dance', she forms a false belief. ${ }^{16}$ Whether or not we want to say that this would count as a belief formed on the basis of testimony, false belief is not knowledge.

Of course, my daughter is not the only person to whom I could profess my love of the tarantella and I doubt I am the only person according to whose standard of taste the tarantella is a lovely dance. When someone with a similar standard of taste forms such a belief, their belief would not be false. Nonetheless, unless they have some general assurance about how similar our tastes are, it seems fairly clear that they would still not gain knowledge. One way to make this clear is to point out that their belief is neither sensitive nor safe. It is insensitive: they would have come to believe that the tarantella is a lovely dance regardless of whether the dance was lovely according to their standards of taste (i.e., regardless of whether the content believed is true). It is unsafe: they would have formed a false belief, had I uttered instead, e.g., 'The tarantella is not a lovely dance'. Some unusual cases might allow knowledge (or at least a very high level of justification), and I think this matches our intuitions. Forming aesthetic beliefs, based on the testimony of those who we know to have very similar tastes to our own, seems to be less problematic. ${ }^{17}$ When I form a belief upon the basis of my wife's testimony, 'marshmallows taste disappointing', I may form a highly justified belief, because we have very similar tastes and we know this. As I have noted, this is not a strict paradigmatic case of testimony. I form a belief with content she did not express because the indexicality

\footnotetext{
${ }^{14}$ Indeed, it is due to this that the problem with testimony arises. We do not think that a relativisation of sentence truth causes problems in cases where the relativity is transparent to us, e.g., 'here', 'now', and 'your mother'.

${ }^{15}$ The conversation in which A says, 'this is my mother', and B (a non-sibling) replies 'no this is not my mother' involves a deep infelicity. But we detect no infelicity in the following conversation: A says 'the tarantella is a lovely dance', B replies, 'No, it isn't!'

${ }^{16}$ The case is akin to that in which I call my partner, who is in the UK, upon my safe arrival in Australia, I say 'I got here safe', and my partner forms the belief that I am in the UK.

${ }^{17} \mathrm{Or}$ indeed some X of whom I know that if it is to X's tastes it is to mine. (Consider the analogous case in epistemology of someone in a high stakes context testifying to someone in a low stakes context that someone knows.)
} 
in her sentence is hidden to me. Nonetheless, the account makes sense of the intuitions.

Non-indexical speaker relativism: This view doesn't say that the contribution 'is a lovely dance' makes to the content of the sentences in which it appears varies. It says instead that the content expressed by 'The tarantella is a lovely dance' is (the tarantella is a lovely dance): a proposition whose truth value is relative to the standard of taste of the speaker. This allows my exchange with my daughter to be nearer a paradigmatic case of testimony-my daughter forms a belief with the same content as I express. Why can't this be knowledge? It is because that content is false relative to her standard of taste. Any belief she forms on the basis of this testimony would be false, and so not knowledge. If, again, we set my daughter aside, and consider my testifying to someone whose tastes are similar to my own, but who is ignorant of that similarity, there is still a problem. Their belief is not sensitive. Were their tastes such that their belief would be false, they would still believe that the tarantella was lovely. Their belief is not safe. Had I asserted 'The tarantella is not a lovely dance', they would have believed it. Forming aesthetic beliefs on the basis of testimony, from those about whose tastes one knows very little, is problematic - any true beliefs one forms will be very lucky. Again, it is less problematic with respect to those whose aesthetic tastes we know much about, so the account could explain why we seem more justified in accepting on testimony the aesthetic beliefs of such individuals (and indeed why it might be more intuitive that we can gain knowledge in such cases). ${ }^{18}$

Both versions of speaker relativism seem to explain the first set of intuitions; if the content of aesthetic assertions is speaker relative, and we are not aware of the truth relativity of such contents, then any true beliefs formed on the basis of aesthetic testimony are too lucky to be knowledge. Let's look at assessor relativism.

Indexical assessor relativism: This view supposes that 'is a lovely dance' contains a hidden indexical. It modifies the content such that as assessed by me the content is P1: 〈the tarantella is a lovely dance for James Andow). But as assessed by my daughter it is P2: (the tarantella is a lovely dance for Timinyo). Suppose my daughter forms a belief with the content P1. This involves a mistake, as assessed by her, this was not what I asserted. Moreover, it is uninformative, it doesn't give her what aesthetic testimony is supposed to give. Suppose she forms a belief with the content P2. Here she forms a false belief, and hence non-knowledge.

Suppose I know testify to someone with similar tastes to me, X, who doesn't know this. Suppose they form the belief (the tarantella is a lovely dance for $\mathrm{X}$ ). Their belief is true, but too lucky to be knowledge. It is insensitive. They would have come to believe that the tarantella is a lovely dance regardless of whether the dance was lovely according to their standards of taste (i.e., regardless of whether the content believed is true). It is unsafe. They would have formed a false belief, had I uttered instead, e.g., 'The tarantella is not a lovely dance'. Again if $\mathrm{X}$ has similar tastes to me, and knows this, knowledge via testimony is easier for them to acquire. However, again, note that this fits with our intuitions.

Non-indexical assessor relativism: This view says the content expressed by 'The tarantella is

\footnotetext{
${ }^{18}$ I take it that the pessimist concedes this point about intuitions, even if they think intuitions are misguided on this point. The intuition that testimony is insufficient for knowledge is much stronger in the case of a testifier about whom one knows very little.
} 
a lovely dance' is (the tarantella is a lovely dance): a proposition whose truth value is relative to the standard of taste of the assessor. Again, if my daughter forms a belief with this content, then she has a belief which is false (as assessed by here), which violates plausible norms for belief and doesn't look much like knowledge. If, again, set my daughter aside, and consider my testifying to someone whose tastes are similar to my own, but who is ignorant of that similarity, there is still a problem. Their belief is not sensitive. Were their tastes such that their belief would be false (as assessed by them), they would still believe that the tarantella was lovely. Their belief is not safe. Had I asserted 'The tarantella is not a lovely dance', they would have believed it. Again if they have similar tastes to me, and know this, knowledge via testimony is easier for them to acquire. However, again, this fits with our intuitions.

So all four views would seem to account for the first set of intuitions. Let's consider the second set of intuitions. These are the intuitions that, in most usual cases, the following assertions are unacceptable, 'the film is absolutely superb, although I have never seen it' and 'the film is absolutely superb' by someone who has never seen the film (without appropriate qualifications). If we suppose that the knowledge norm of assertion holds, then it is clear why these assertions are unacceptable. It is very difficult to know the content asserted by 'the film is absolutely superb' via testimony due on either account due to the problems given above. Moreover, this seems the only likely candidate for a source of justification (if the belief is justified) in the relevant cases. ${ }^{19}$

Again, maybe it is possible to gain aesthetic knowledge via testimony from those whose aesthetic tastes are very in tune with one's own. However, this meshes nicely with our intuitions. In such cases, such assertions will be more acceptable. It is more acceptable for me to assert that, 'I have never seen the film, though it is a great film,' if I lean on the testimony of my partner, with whose opinion of a film I have never disagreed, than if I rely upon a newspaper review, with whose verdict I frequently disagree.

\section{Wrapping Up}

One final reason to think that such an account might have some merits is to consider testimony in the case of other (non-taste) predicates for which a (hidden) context sensitivity type view might be offered, e.g., 'is tall'. I think that there are possible problems with testimony here too. It is not quite analogous (not a speaker relative case), but I think is helpful. When I tell my mother that, 'Jones, the basketball player, is short', she, not knowing enough about basketball, forms a belief she would express using the same sentence, with the content 〈Jones is five foot six or less), which is false. When she says 'Jones, the basketball player, is short, although I know nothing about how tall basketball players usually are', there is something odd about her assertion (especially once we know how she acquired the belief).

\footnotetext{
${ }^{19}$ There are other possibilities. Perhaps the quality of the film has been inferred from the quality of the plot line which has been communicated some other way, cinematography in the trailer, the actors, the quality of previous output by the director, etc. Note, however, that the relevant qualifications remove the infelicity of the assertions, e.g., 'the film is superb, I have never seen it, but everything this director makes is superb'.
} 
To conclude, I should note that I appreciate the argument is quick and I have not looked carefully at the large body of intuitions which might be relevant to these matters. The purpose of the paper is simply to note that it seems that an account of aesthetic predicates, which has the result that sentences containing such predicates have speaker or assessor relative truth values, stands a good chance of making sense of why aesthetic testimony and associated assertions seem to present a particular puzzle. It is because the relativistic nature of the predicates disrupts the usual testimonial process.

\section{Acknowledgements}

This is a preprint version of a paper published in Acta Analytica (Andow, 2015). Please rely on final version for citations.

Thanks to Greg Currie and Jon Robson for very helpful comments. Thanks also to members of an audience in Nottingham. Acknowledgment is also due to the support of an AHRCfunded studentship.

\section{References}

Andow, J. (2015). A semantic solution to the problem with aesthetic testimony, Acta Analytica 30(2): 211-218.

URL: $h t t p: / / d x$.doi.org/10.1007/s12136-014-0238-4

Hopkins, R. (2001). Kant, quasi-realism, and the autonomy of aesthetic judgement, European Journal of Philosophy 9(2): 166-189.

Hopkins, R. (2006). How to form aesthetic belief: Interpreting the acquaintance principle, Postgraduate Journal of Aesthetics 3(3): 85-99.

Hopkins, R. (2011). How to be a pessimist about aesthetic testimony, The Journal of Philosophy 108(3): 138-157.

Laetz, B. (2008). A modest defense of aesthetic testimony, The Journal of Aesthetics and Art Criticism 66(4): 355-363.

Lasersohn, P. (2005). Context dependence, disagreement, and predicates of personal taste, Linguistics and Philosophy 28(6): 643-686.

MacDowell, J. H. (1998). Meaning, knowledge, and reality, Harvard University Press.

MacFarlane, J. (2005). The assement sensitivity of knowledge attributions, in T. S. Gendler and J. Hawthorne (eds), Oxford Studies in Epistemology, Vol. 1, Oxford University Press, pp. 197-233.

MacFarlane, J. (2014). Assessment Sensivity: Relative Truth and its Applications, OUP. 
Matravers, D. (2010). Aesthetic relativism, Postgraduate Journal of Aesthetics 7(1): 1-12.

McGonigal, A. (2006). The autonomy of aesthetic judgement, The British Journal of Aesthetics 46(4): 331-348.

Meskin, A. (2004). Aesthetic testimony: What can we learn from others about beauty and art?, Philosophy and Phenomenological Research 69(1): 65-91.

Robson, J. (2012). Aesthetic testimony, Philosophy Compass 7(1): 1-10.

Robson, J. (2013a). Aesthetic testimony and the norms of belief formation, European Journal of Philosophy (online first).

Robson, J. (2013b). Appreciating the acquaintance principle: A reply to konigsberg, British Journal of Aesthetics 53(2): 237-245.

Smith, B. (2010). Relativism, disagreement and predicates of personal taste, in F. Recanati, I. Stojanovic and N. Villanueva (eds), Context-dependence, Perspective and Relativity, De Gruyter, pp. 195-225.

Smith, B. (2012). Relativism about truth and predicates of taste, Filosofia Unisinos 13(2suppl.): 250-265.

Wollheim, R. (1980). Art and its Objects: With Six Supplementary Essays, Cambridge University Press. 